\title{
Hepatitis B virus infection and decreased risk of stroke: a meta- analysis
}

\author{
Yaqin Wang ${ }^{1}$, Jianping Xiong ${ }^{2}$, Xi Chen ${ }^{3}$, Meng Niu ${ }^{1}$, Xiaowei Chen ${ }^{1}$, Yuheng Guan ${ }^{1}$, \\ Kechuang Zheng ${ }^{1}$ and $\mathrm{Ke} \mathrm{X}^{1}$ \\ ${ }^{1}$ Department of Interventional Radiology, The First Affiliated Hospital of China Medical University, Shenyang, China \\ ${ }^{2}$ Department of Liver Surgery, Peking Union Medical College Hospital, Chinese Academy of Medical Sciences and Peking Union \\ Medical College (CAMS and PUMC), Beijing, China \\ ${ }^{3}$ Department of Orthopedic Surgery, Peking Union Medical College Hospital, Peking Union Medical College and Chinese Academy of \\ Medical Sciences, Beijing, China
}

Correspondence to: Ke Xu, email: kexu@vip.sina.com

Keywords: hepatitis B virus, stroke, cerebrovascular disease, meta-analysis

Received: June 08, 2017

Accepted: July 13, 2017

Published: July 26, 2017

Copyright: Wang et al. This is an open-access article distributed under the terms of the Creative Commons Attribution License 3.0 (CC BY 3.0 ), which permits unrestricted use, distribution, and reproduction in any medium, provided the original author and source are credited.

\section{ABSTRACT}

Several studies have reported that hepatitis B virus (HBV) infection may decrease the risk of stroke. However, its association is controversial. Thus, we conducted a systematic review and meta-analysis to investigate the relationship between hepatitis B virus (HBV) infection and the risk of stroke. Relevant studies published before May 2017 were identified by searching PubMed, EMBASE, and ISI Web of Science. The relationships between HBV infection and the risk of stroke were assessed using odds ratio (OR)/risk ratio ( $R R$ ) values and the corresponding $\mathbf{9 5 \%}$ confidence intervals (CIs). We used the random effects model proposed by DerSimonian and Laird to quantify the relationship. Five articles, including 834,75 HBV-infected patients and 593,949 uninfected controls, were included in the meta-analysis. The risk of stroke was significantly lower in HBV-infected patients than in uninfected controls (summary $\mathrm{OR}=0.78 ; 95 \% \mathrm{CI}=0.70-0.86$; $\left.I^{2}=0 \%\right)$. However, this inverse relationship was only observed in cohort studies $(O R=0.77 ; 95 \% C I=0.69-0.86)$, rather than cross-sectional study $(O R=1.10$; 95\% CI $=0.55-2.19$ ). In summary, HBV infection was associated with lower risk of developing stroke.

\section{INTRODUCTION}

Hepatitis B infection is a global health burden. An estimated 350 million people $-5 \%-7 \%$ of the world's population - are chronic carriers of the hepatitis $\mathrm{B}$ virus (HBV) $[1,2]$. Moreover, hepatitis B is the leading cause of chronic liver disease, especially cirrhosis and hepatocellular carcinoma [3]. At least one-third of patients with cirrhosis and $75 \%$ of patients with primary liver cancer have hepatitis B [4,5], and approximately 1 million people die of acute and chronic HBV infection every year [6]. Recently, researchers have reported an inverse relationship between HBV infection and metabolic syndrome [7] and have found that HBV infection is also an independent factor associated with a lower risk of fatty liver [8-10]. Furthermore, studies reported HBV infection may decrease the risk of stroke [11]. However, this association is controversial [12-16]. Stroke is a leading public health problem that affects millions of people in developed and developing countries [17]. Stroke is the second leading cause of death after ischemic heart disease [18]. The proportion of deaths attributed to stroke is $10-12 \%$ in western countries, and $12 \%$ of these deaths are in people less than 65 years of age [19]. Although the mortality rate of cerebrovascular has decreased in some countries over the past decades, it is still the leading cause of death in the United States, Europe and most parts of Asia [20, 21]. Thus, to better understand the relationship between HBV infection and the risk of stroke, we conducted a systematic review and meta-analysis of published observational studies. 


\section{RESULTS}

\section{Study selection and study characteristics}

Figure 1 shows the process of study selection for the meta-analysis. We obtained 12,025 articles through the initial search, of which 2706 were duplicates. A further 9,319 studies were excluded based on title and abstract review. Finally, after five studies were further excluded due to providing insufficient information [22-26], five eligible observational articles [12-16] were identified for our meta-analysis.

The main characteristics of the included studies are listed in Table 1 [12-16]. The studies were performed in the following countries: two in Taiwan, one in Germany, one in England, and one in Canada. All included studies were observational studies. Four studies had a cohort design, and one study had cross-sectional design. A metaanalysis was performed to examine the effect of HBV infection on the risk of stroke, which included 834,75 HBV-infected patients and 593,949 uninfected controls. The data collection period ranged from 1990 to 2007. The modified NOS scores for included studies ranged from 6 to 9 , with four high quality studies and only one medium quality studies (Table 3).

\section{Association between HBV infection and the risk of stroke}

Four cohort and one cross-sectional studies [12-16] that evaluated the effect of HBV infection on the risk of stroke were identified (Table 1). Two studies suggested HBV infection was associated with decreased the risk of stroke. The remaining of the studies did not show any relationship between HBV infection and the risk of stroke. The pooled estimate of the effect of HBV infection was significant $(\mathrm{OR}=0.78 ; 95 \% \mathrm{CI}=0.70-0.86)$, and the studies exhibited no significant heterogeneity $\left(\mathrm{I}^{2}=0 \%\right.$; $p=0.519$ ) (Figure 2). The risk of stroke was significantly lower in HBV-infected patients than in uninfected controls. However, this inverse relationship was only observed in cohort studies $(\mathrm{OR}=0.77 ; 95 \% \mathrm{CI}=0.69-0.86)$, rather than cross-sectional $(\mathrm{OR}=1.10 ; 95 \% \mathrm{CI}=0.55-2.19)$ (Table 2).

\section{Subgroup and sensitivity analyses}

The results of subgroup analyses are shown in Table 2. The analysis was stratified by geographic area, years of publication, study design and whether alcohol intake, smoking or diabetes were adjusted for in the models. When the studies from Western countries (Germany, England, and Canada) and Eastern countries were analyzed, no significant difference was found between the two areas. According to the sensitivity analyses, despite excluding studies with an NOS score $<7$, the relationship between HBV and stroke remained stable. Additionally, the overall results for the relationships of HBV infection to stroke were maintained when the pooling model was altered (Table 2). Besides, when we sequentially excluded one study in one turn to assess the stability of the results, no study could possibly affect the pooled risk estimate (Figure 3).

\section{Publication bias}

No testing for funnel plot asymmetry was performed because of the restricted number of included studies in the analysis $(n<10)$; however, Begg's $(p=0.417)$ and Egger's $(p=0.325)$ tests did not identify substantial publication bias.

\section{DISCUSSION}

Previous studies that have explored the relationship between hepatitis $\mathrm{C}$ virus infection and cerebrovascular disease have found that hepatitis $\mathrm{C}$ virus infection was associated with an increased risk of stroke [27, 28]. However, few studies have examined the effect of HBV infection on the risk of stroke and this association is still controversial. To our knowledge, this is the first metaanalysis to investigate the relationship between HBV infection and the risk of stroke. We found that the risk of stroke was significantly lower in $\mathrm{HBV}$-infected patients than in uninfected controls $(\mathrm{OR}=0.78 ; 95 \% \mathrm{CI}=0.70$ 0.86 ). This effect was only observed in cohort studies. However, the cross-sectional study did not reveal any relationship between $\mathrm{HBV}$ infection and the risk of stroke.

Our study only demonstrated an association between the HBV infection and a reduced risk of stroke; the data cannot establish a causative role for HBV in this regard. However, if such a causative role is present, possible mechanisms could be the following. Firstly, HBV infection can lead to progressive fibrosis and even cirrhosis of the liver. Previous studies have suggested that liver cirrhosis has an inverse relationship with the risk of atherosclerosis, which may be associated with an impaired coagulant function and decreased atherogenic risk factors, such as triglyceride and cholesterol levels [29-31]. Secondly, patients with HBV infection may exhibit an increase in some cytokines, such as hepatocyte growth factor, which may play a role in anti-atherosclerosis effects by protecting the vascular endothelium $[32,33]$. Thirdly, hepatitis B patients may be pay more attention to physical activity and have a good dietary habits, which previous studies have indicated the effect of it on the development of cerebrovascular disease [34-37].

Our study has several strengths. First, it is the first meta-analysis with large sample size (834,75 HBV-infected patients and 593,949 uninfected controls) to explore the relationship between $\mathrm{HBV}$ infection and the risk of stroke, and may provide insight into this relationship. Second, we performed subgroup and sensitivity analyses to identify 


\section{Table 1: The main characteristics of the included studies}

\begin{tabular}{|c|c|c|c|c|c|c|c|c|c|}
\hline $\begin{array}{l}\text { Study/Years } \\
\text { of } \\
\text { Publication }\end{array}$ & Country & HBV+/HBV- & Follow & $\begin{array}{l}\text { Sources of } \\
\text { Controls }\end{array}$ & $\begin{array}{l}\text { Subtype } \\
\text { of } \\
\text { study }\end{array}$ & Exposure & Adjusted Factors & Outcome & $\begin{array}{l}\text { Adjusted OR/ } \\
\text { RR (95\% CI) }\end{array}$ \\
\hline Tseng.2016 & Taiwan & $22303 / 89212$ & $2000-2006$ & population & cohort & HBV & $\begin{array}{l}\text { sex, age, hyperlipidemia, diabetes, } \\
\text { hypertension, IHD, AF, ALD, and LC } \\
\text { with the Cox proportional hazards } \\
\text { regression model }\end{array}$ & stroke & $0.77(0.66-0.89)$ \\
\hline Sung.2007 & England & $56576 / 478747$ & $1990-2001$ & population & cohort & $\mathrm{HBV}$ & $\begin{array}{l}\text { age, body mass index, height, serum } \\
\text { glucose, hypertension categories, } \\
\text { lipid categories, ethanol consumption, } \\
\text { smoking, physical activity, monthly pay } \\
\text { level, and area of residence. }\end{array}$ & stroke & $0.79(0.68,0.90)$ \\
\hline Wang.2010 & Taiwan & $3931 / 18541$ & $1991-2007$ & population & cohort & HBV & age, sex & stroke & $1.00(0.69-1.44)$ \\
\hline Völzke.2004 & Germany & $233 / 4033$ & $1997-2001$ & population & $\begin{array}{c}\text { cross- } \\
\text { sectional }\end{array}$ & $\mathrm{HBV}$ & $\begin{array}{c}\text { sex, age, current smoking, diabetes, } \\
\text { hypertension, body mass index, total } \\
\text { cholesterol/HDL ratio, plasma fibrinogen } \\
\text { levels }\end{array}$ & stroke & $1.10(0.55-2.19)$ \\
\hline Gillis.2014 & Canada & $432 / 3416$ & 2003-2007 & population & cohort & $\begin{array}{l}\mathrm{HBV} / \\
\mathrm{HIV}\end{array}$ & $\begin{array}{l}\text { age, sex, race, year of ART initiation, } \\
\text { weight and baseline smoking status }\end{array}$ & stroke & $1.05(0.63,1.74)$ \\
\hline
\end{tabular}

HBV, hepatitis B virus. HIV, Human Immunodeficiency Virus. RR, relative risk. OR, odds ratio. CI, confidence interval. BMI: body mass index. NR: none report.
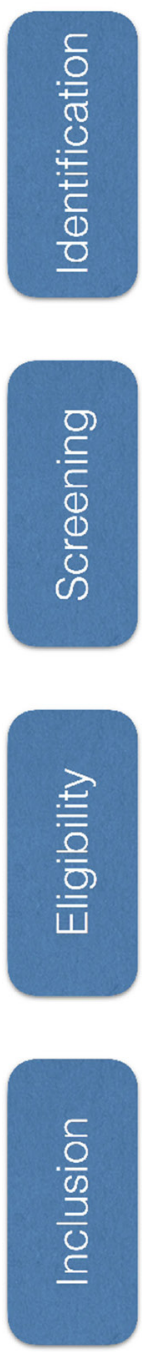

Record identified through

Pubmed(n=2018)

Web of science $(n=6579)$

Embase $(n=3428)$

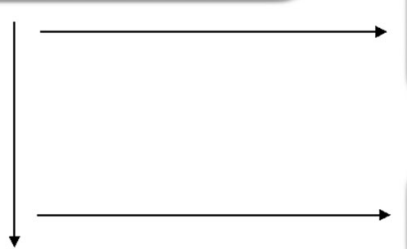

Records excluded based on title and $\operatorname{abstract}(\mathrm{n}=9319)$

Duplicates studies(n=2706)

Articles identified for further review $(n=334)$

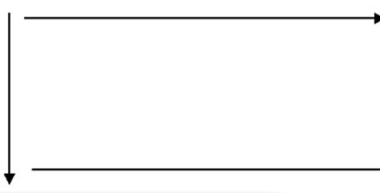

No relevant studies $(\mathrm{n}=305)$

Studies design not case-control, crosssectional, or cohort $(\mathrm{n}=19)$

Full text articles assessed for eligibility $(n=10)$

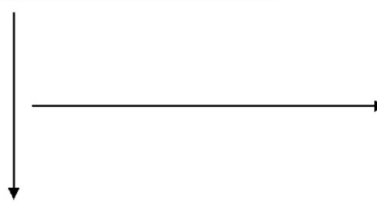

Provide no sufficient date $(\mathrm{n}=5)$

Studies included in final analysis

Cohort studies $(n=4)$

Cross-sectional studies $(\mathrm{n}=1)$

Figure 1: The process of study selection for the meta-analysis. 
Table 2: Subgroup and sensitivity analyses of the effect of HBV infection on the risk of stroke

\begin{tabular}{|c|c|c|c|c|}
\hline Subgroup & No. of studies & RR $(95 \% C I)$ & $I^{2}$ value $(\%)$ & $P$ value \\
\hline All studies & 5 & $0.78(0.70,0.86)$ & 0 & 0.519 \\
\hline \multicolumn{5}{|l|}{ Geographic areas } \\
\hline West & 3 & $0.76(0.64,0.88)$ & 0 & 0.405 \\
\hline East & 2 & $0.81(0.64,0.99)$ & 24.3 & 0.250 \\
\hline \multicolumn{5}{|l|}{ Years of publication } \\
\hline$\geq 2010$ & 3 & $0.81(0.68,0.94)$ & 6.3 & 0.344 \\
\hline$<2010$ & 2 & $0.75(0.62,0.87)$ & 0 & 0.395 \\
\hline \multicolumn{5}{|l|}{ Study design } \\
\hline Cohort studies & 4 & $0.77(0.69,0.86)$ & 0 & 0.452 \\
\hline Cross-sectional studies & 1 & $1.10(0.55,2.19)$ & - & - \\
\hline \multicolumn{5}{|l|}{ Adjustment for confounders } \\
\hline \multicolumn{5}{|l|}{ Diabetes } \\
\hline Yes & 3 & $0.76(0.68,0.84)$ & 0 & 0.674 \\
\hline No & 2 & $1.02(0.70,1.33)$ & 0 & 0.884 \\
\hline \multicolumn{5}{|l|}{ Alcohol intake } \\
\hline Yes & 1 & $0.79(0.68,0.90)$ & - & - \\
\hline No & 4 & $0.80(0.70,0.91)$ & 0 & 0.450 \\
\hline \multicolumn{5}{|l|}{ Smoking } \\
\hline Yes & 2 & $0.75(0.62,0.87)$ & 0 & 0.395 \\
\hline No & 3 & $0.81(0.68,0.94)$ & 6.3 & 0.344 \\
\hline \multicolumn{5}{|l|}{ Sensitive analyses } \\
\hline High-quality studies & 4 & $0.77(0.69,0.86)$ & 0 & 0.452 \\
\hline \multicolumn{5}{|c|}{ Fixed-effects vs random-effects model method } \\
\hline Fixed-effects model & 5 & $0.78(0.70,0.86)$ & 0 & 0.519 \\
\hline Random-effects model & 5 & $0.78(0.70,0.86)$ & 0 & 0.519 \\
\hline
\end{tabular}

HBV, hepatitis B virus. RR, relative risk; CI, confidence interval.

Table 3: Scores of the modified Newcastle-Ottawa scale for studies

\begin{tabular}{|c|c|c|c|c|c|c|c|c|c|}
\hline $\begin{array}{c}\text { Study/Years } \\
\text { of } \\
\text { Publication }\end{array}$ & $\begin{array}{c}\text { Fully } \\
\text { defined } \\
\text { cases }\end{array}$ & $\begin{array}{c}\text { Define } \\
\text { the study } \\
\text { design }\end{array}$ & $\begin{array}{l}\text { Selection } \\
\text { of controls }\end{array}$ & $\begin{array}{c}\text { Described } \\
\text { the general } \\
\text { characteristics }\end{array}$ & $\begin{array}{l}\text { Controlling } \\
\text { the important } \\
\text { factors or } \\
\text { confounding } \\
\text { factors }\end{array}$ & $\begin{array}{l}\text { List inclusion } \\
\text { and exclusion } \\
\text { criteria for all } \\
\text { the participants }\end{array}$ & $\begin{array}{c}\text { Provided } \\
\text { enrollment } \\
\text { duration } \\
\text { for all the } \\
\text { participants }\end{array}$ & $\begin{array}{c}\text { Indicate } \\
\text { study period } \\
\text { and follow- } \\
\text { up duration }\end{array}$ & $\begin{array}{l}\text { Total } \\
\text { score }\end{array}$ \\
\hline Gillis. 2014 & $*$ & $*$ & $*$ & $*$ & $*$ & $*$ & $*$ & & 8 \\
\hline Wang. 2010 & $*$ & $*$ & $*$ & $*$ & $*$ & $*$ & $*$ & & 7 \\
\hline Sung. 2007 & $*$ & $*$ & $*$ & $*$ & $* *$ & $*$ & $*$ & $*$ & 9 \\
\hline Tseng. 2016 & $*$ & $*$ & & $*$ & $* *$ & * & $*$ & $*$ & 8 \\
\hline Völzke. 2004 & $*$ & $*$ & & & $* *$ & $*$ & $*$ & & 6 \\
\hline
\end{tabular}

the factors that affect these risks, which strengthened our findings. Third, we performed a comprehensive literature search, which was based on the PubMed, EMBASE and Web of Science, to identify potential studies to investigate relationships between HBV infection and the risk of stroke. Besides, most of the studies included in our meta-analysis were of high quality. All of these characteristics make the conclusions of our study more convincing.

There are several limitations that must be considered. First, only five studies were included in our article to investigate the relationship between HBV infection and the risk of stroke, and due to the different study designs, quality score of the study and demographic characteristics inconsistency, this puts the meta-analysis at high risk of publication bias and clinical heterogeneity and may be considered another potential limitation of this study. Second, the outcome that we observed was an association, which is subject to confounding bias. Although we considered a number of adjustment factors, many potential adjustment factors were unknown, such 


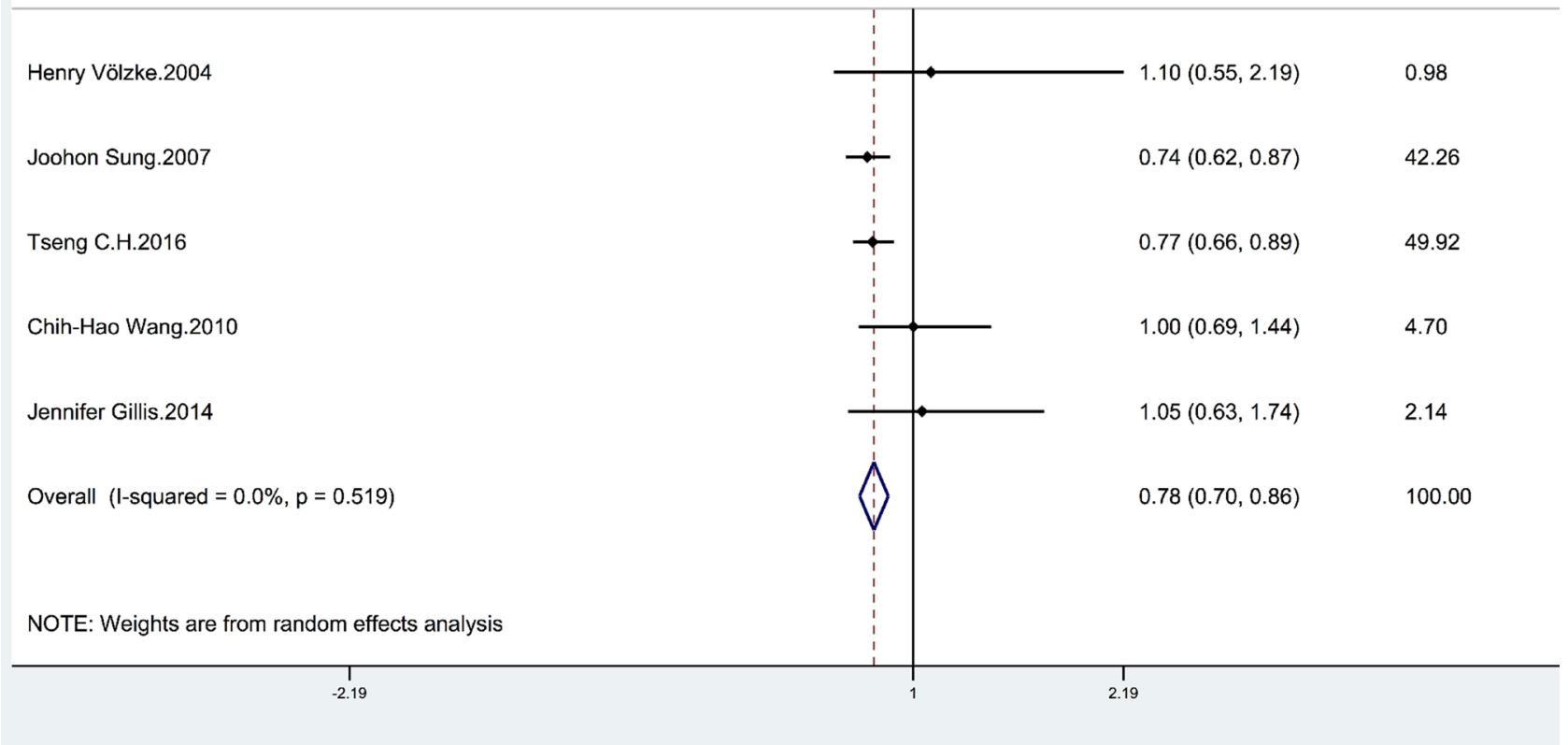

Figure 2: Forrest plot showing the relationship between HBV infection and the risk of stroke. Points represent the risk estimates for each individual study. Horizontal lines represent $95 \%$ confidence intervals, and diamonds represent the summary risk estimates with $95 \%$ confidence intervals. HBV, hepatitis B virus. CI, confidence interval. ES, effect size.

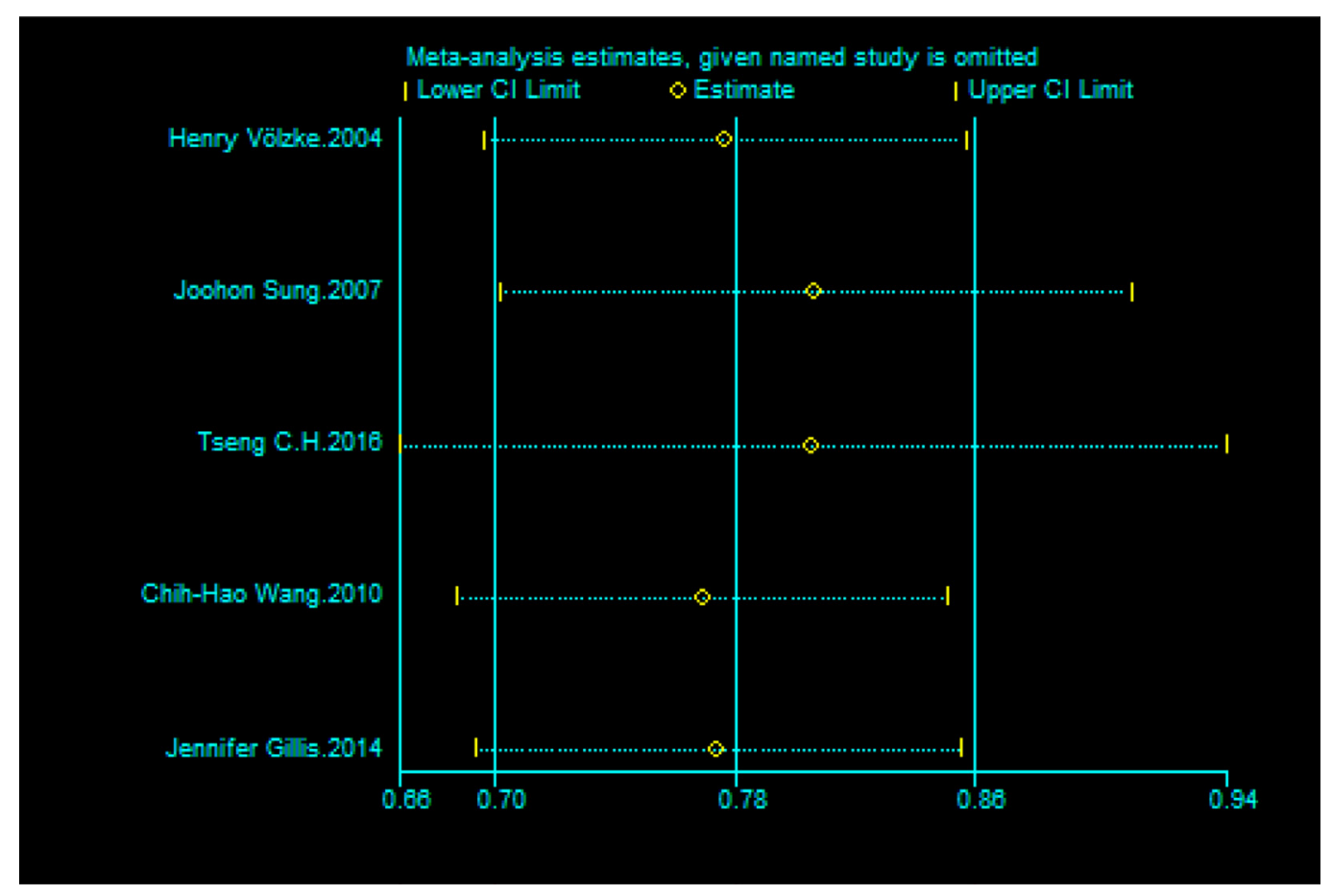

Figure 3: Sensitivity analysis of the association between HBV infection and the risk of stroke. 
as cholesterol levels, cirrhosis severity and triglyceride levels, which are closely related to the development of cerebrovascular disease. In addition, we failed to obtain information about antiviral treatment in patients with $\mathrm{HBV}$, which could have influenced the development of cerebrovascular disease. Third, Gillis 2014 [16] only included patients with HIV/HBV co-infection. It is known that HIV itself may also affect cerebrovascular disease risk $[38,39]$; thus, our findings may not be generalizable to all populations. Finally, most of the studies included in our meta-analysis were cohort studies, but there is still a crosssectional study. Cross-sectional design is prone to generate recall and selection biases, and has an insufficient power to evaluate the relationship between $\mathrm{HBV}$ infection and the risk of stroke.

In summary, our meta-analysis indicated that the risk of stroke was $22 \%$ lower in HBV-infected patients than in uninfected controls. This effect was only observed in cohort studies. However, the cross-sectional study did not reveal any relationship between HBV infection and the risk of stroke. Therefore, more prospective and basic research studies are urgently needed to further validate the association between HBV infection and the risk of stroke.

\section{MATERIALS AND METHODS}

\section{Data sources and search strategy}

We searched published reports in PubMed, EMBASE and Web of Science using the following keywords: ("hepatitis B" OR "hepatitis B virus" OR "HBV") and ("cardiovascular disease" OR "stroke" OR "cerebrovascular disease" OR "transitory ischemic attack"). We placed no restrictions on the language or the date of publication.

\section{Eligibility criteria for study selection}

The eligibility criteria were as follows: study design (case control, cross-sectional or cohort); an exposure factor of HBV and an outcome of cerebrovascular disease or stroke; and availability of the odds ratio (OR)/risk ratio (RR) values and corresponding 95\% confidence intervals (CIs) in the HBV-positive and HBV-negative groups or sufficient information provided to enable calculation of these variables. If two studies reported the same data, we selected the study with the larger sample size.

\section{Data abstraction and quality assessment}

Two researchers (JPX and YQW) independently extracted the required information from the selected reports in a standardized manner. The following information was collected from each article: year of publication, first author's name and country of origin, study design (crosssectional, case-control or cohort), number of participants (cases, controls, or cohort size), duration of followup, sources of controls, potential adjusted confounding variables, OR/RR values and 95\% CIs in the HBV-positive and HBV-negative groups.

There is no universal scale available to assess the quality of all kinds of observational studies. Thus, two authors independently use the modified NewcastleOttawa Scales (NOS) [40] reported by Wei Zhu [41] to evaluate the quality of included studies. Quality categories were assigned according to the scores of each study. The categories included high quality (score 7-9), medium quality (score 4-6) and low quality (score less than 4) [42]. A maximum total score is 9 points. Discrepancies were resolved by consensus.

\section{Statistical analyses}

The relationships between $\mathrm{HBV}$ infection and the risk of stroke were assessed using OR/RR values and the corresponding 95\% CIs. The hazard ratio was treated as equivalent to the RR. The random effects model proposed by DerSimonian and Laird was used to quantify the relationship between $\mathrm{HBV}$ infection and the risk of stroke [43]. HBV infection was defined as the presence of HBsAg in our meta-analysis.

The I2 statistic was used to assess heterogeneity between studies, and low, medium, and high heterogeneity were defined as $25 \%, 50 \%$, and $75 \%$, respectively [44]. If the $p$ value was less than 0.1 , definite heterogeneity was assumed. Publication bias was evaluated with Begg's [45] and Egger's [46] tests; however, no testing for funnel plot asymmetry was performed because of the restricted number of included studies in the analysis $(n<10)$ [47].

Subgroup analyses were performed by geographic area, years of publication, study design and whether alcohol intake, smoking or diabetes were adjusted for in the models. Sensitivity analyses were performed by changing the pooling model (random-effects model or fixed-effects model) and excluding studies with NOS scores $<7$ [48]. Sensitivity analysis was also performed to assess the effect of every study on the summarized estimate by sequentially excluding one study in one turn [49].

All statistical analyses were performed with STATA version 12.0 (Stata).

\section{Abbreviations}

HBV, hepatitis B virus. HCV, hepatitis $\mathrm{C}$ virus. RR, relative risk. $\mathrm{OR}$, odds ratio. $\mathrm{CI}$, confidence interval.

\section{Authors' contributions}

YQW conceived the study and wrote this manuscript. JPX and YQW searched database, reviewed studies and collected date. $\mathrm{MN}, \mathrm{XWC}, \mathrm{KCZ}, \mathrm{YHG}$ and $\mathrm{XC}$ performed statistical analyses. $\mathrm{KX}$ coordinated and 
provided financial support for this work. All authors reviewed the manuscript and contributed to manuscript revisions. $\mathrm{KX}$ is the guarantor for this study.

\section{CONFLICTS OF INTEREST}

None.

\section{FUNDING}

This work was supported by the National Natural Science Foundation of China (81601584).

\section{REFERENCES}

1. Alter MJ. Epidemiology of hepatitis B in Europe and worldwide. Journal of Hepatology. 2003; 39:64-69.

2. Kao JH, Chen DS. Global control of hepatitis B virus infection. The Lancet Infectious Diseases. 2002; 2:395-403.

3. Liaw YF, Chu CM. Hepatitis B virus infection. The Lancet. 373:582-592.

4. Chu CM, Liaw YF. Hepatitis B virus-related cirrhosis: natural history and treatment. Seminars in liver disease. 2006; 26:142-152.

5. Beasley RP. Hepatitis B virus. The major etiology of hepatocellular carcinoma. Cancer. 1988; 61:1942-1956.

6. Kane M. Global programme for control of hepatitis B infection. Vaccine. 1995; 13:S47-49.

7. Wang CC, Tseng TC, Kao JH. Hepatitis B virus infection and metabolic syndrome: fact or fiction? J Gastroenterol Hepatol. 2015; 30:14-20.

8. Cheng YL, Wang YJ, Kao WY, Chen PH, Huo TI, Huang YH, Lan KH, Su CW, Chan WL, Lin HC, Lee FY, Wu JC. Inverse Association between Hepatitis B Virus Infection and Fatty Liver Disease: A Large-Scale Study in Populations Seeking for Check-Up. PLoS ONE. 2013; 8:e72049.

9. Joo EJ, Chang Y, Yeom JS, Ryu S. Hepatitis B virus infection and decreased risk of nonalcoholic fatty liver disease: A cohort study. Hepatology (Baltimore, Md). 2016; 65:828-835.

10. Wong VW, Wong GL, Chu WC, Chim AM, Ong A, Yeung DK, Yiu KK, Chu SH, Chan HY, Woo J, Chan FK, Chan HL. Hepatitis B virus infection and fatty liver in the general population. J Hepatol. 2012; 56:533-540.

11. Mozaffarian D, Benjamin EJ, Go AS, Arnett DK, Blaha MJ, Cushman M, de Ferranti S, Despres JP, Fullerton HJ, Howard VJ, Huffman MD, Judd SE, Kissela BM, et al. Heart Disease and Stroke Statistics-2015 Update A Report From the American Heart Association. Circulation. 2015; 131:E29-E322.

12. Tseng $\mathrm{CH}$, Muo $\mathrm{CH}$, Hsu CY, Kao CH. Association of hepatitis B virus infection with decreased ischemic stroke. Acta neurologica Scandinavica. 2016; 134:339-345.
13. Sung J, Song YM, Choi YH, Ebrahim S, Davey Smith G. Hepatitis B virus seropositivity and the risk of stroke and myocardial infarction. Stroke. 2007; 38:1436-1441.

14. Wang CH, Chen CJ, Lee MH, Yang HI, Hsiao CK. Chronic hepatitis $\mathrm{B}$ infection and risk of atherosclerosis-related mortality: A 17-year follow-up study based on 22,472 residents in Taiwan. Atherosclerosis. 2010; 211:624-629.

15. Volzke H, Schwahn C, Wolff B, Mentel R, Robinson DM, Kleine V, Felix SB, John U. Hepatitis B, C virus infection and the risk of atherosclerosis in a general population. Atherosclerosis. 2004; 174:99-103.

16. Gillis J, Smieja M, Cescon A, Rourke SB, Burchell AN, Cooper C, Raboud JM. Risk of cardiovascular disease associated with HCV, HBV coinfection among antiretroviral-treated HIV-infected individuals. Antiviral therapy. 2014; 19:309-317.

17. Yusuf S, Reddy S, Ôunpuu S, Anand S. Global Burden of Cardiovascular Diseases. Part I: General Considerations, the Epidemiologic Transition, Risk Factors, and Impact of Urbanization. 2001; 104:2746-2753.

18. Murray CJL, Lopez AD. Mortality by cause for eight regions of the world: Global Burden of Disease Study. The Lancet. 1997; 349:1269-1276.

19. Donnan GA, Fisher M, Macleod M, Davis SM. Stroke. The Lancet. 371:1612-1623.

20. Smolina K, Wright FL, Rayner M, Goldacre MJ. Determinants of the decline in mortality from acute myocardial infarction in England between 2002 and 2010: linked national database study. BMJ. 2012; 344:d8059.

21. Unal B, Critchley JA, Capewell S. Explaining the decline in coronary heart disease mortality in England and Wales between 1981 and 2000. Circulation. 2004; 109:1101-1107.

22. Kiechl S, Werner P, Egger G, Oberhollenzer F, Mayr M, $\mathrm{Xu} \mathrm{Q}$, Poewe W, Willeit J. Active and passive smoking, chronic infections, and the risk of carotid atherosclerosis: prospective results from the Bruneck Study. Stroke. 2002; 33:2170-2176.

23. Zhao P, Wang C, Wu Y, Liu W. Risk of coronary artery disease in patients with chronic hepatitis B. Journal of Clinical Virology. 2015; 69:223.

24. Karsen H, Binici I, Sunnetcioglu M, Baran AI, Ceylan MR, Selek S, Celik H. Association of paraoxonase activity and atherosclerosis in patients with chronic hepatitis B. African health sciences. 2012; 12:114-118.

25. Bilora F, Rinaldi R, Boccioletti V, Petrobelli F, Girolami A. Chronic viral hepatitis: a prospective factor against atherosclerosis. A study with echo-color Doppler of the carotid and femoral arteries and the abdominal aorta. Gastroenterologie clinique et biologique. 2002; 26:1001-1004.

26. Yang KC, Chen MF, Su TC, Jeng JS, Hwang BS, Lin LY, Liau CS, Lee YT. Hepatitis B virus seropositivity is not associated with increased risk of carotid atherosclerosis in Taiwanese. Atherosclerosis. 2007; 195:392-397.

27. Petta S, Maida M, Macaluso FS, Barbara M, Licata A, Craxi A, Camma C. Hepatitis C Virus Infection Is 
Associated With Increased Cardiovascular Mortality: A Meta-Analysis of Observational Studies. Gastroenterology. 2016; 150:145-155.e144; quiz e115-146.

28. Ambrosino P, Lupoli R, Di Minno A, Tarantino L, Spadarella G, Tarantino P, Nasto A, Celentano A, Di Minno MN. The risk of coronary artery disease and cerebrovascular disease in patients with hepatitis $\mathrm{C}$ : A systematic review and meta-analysis. International journal of cardiology. 2016; 221:746-754.

29. Marchesini G, Ronchi M, Forlani G, Bugianesi E, Bianchi G, Fabbri A, Zoli M, Melchionda N. Cardiovascular disease in cirrhosis-a point-prevalence study in relation to glucose tolerance. The American journal of gastroenterology. 1999; 94:655-662.

30. Liu J, Yang HI, Lee MH, Lu SN, Jen CL, Wang LY, You SL, Iloeje UH, Chen CJ. Incidence and determinants of spontaneous hepatitis B surface antigen seroclearance: a community-based follow-up study. Gastroenterology. 2010; 139:474-482.

31. Joo EJ, Chang Y, Yeom JS, Ryu S. Hepatitis B virus infection and decreased risk of nonalcoholic fatty liver disease: A cohort study. Hepatology (Baltimore, Md). 2016.

32. Nakamura T, Nishizawa T, Hagiya M, Seki T, Shimonishi M, Sugimura A, Tashiro K, Shimizu S. Molecular cloning and expression of human hepatocyte growth factor. Nature. 1989; 342:440-443.

33. Shiota G, Okano J, Kawasaki H, Kawamoto T, Nakamura T. Serum hepatocyte growth factor levels in liver diseases: clinical implications. Hepatology (Baltimore, Md). 1995; 21:106-112.

34. Threapleton DE, Greenwood DC, Evans CE, Cleghorn CL, Nykjaer C, Woodhead C, Cade JE, Gale CP, Burley VJ. Dietary fibre intake and risk of cardiovascular disease: systematic review and meta-analysis. BMJ. 2013; 347:f6879.

35. Ding M, Bhupathiraju SN, Satija A, van Dam RM, Hu FB. Long-term coffee consumption and risk of cardiovascular disease: a systematic review and a dose-response metaanalysis of prospective cohort studies. Circulation. 2014; 129:643-659.

36. Ignarro LJ, Balestrieri ML, Napoli C. Nutrition, physical activity, and cardiovascular disease: an update. Cardiovascular research. 2007; 73:326-340.

37. Soares-Miranda L, Siscovick DS, Psaty BM, Longstreth WT Jr, Mozaffarian D. Physical Activity and
Risk of Coronary Heart Disease and Stroke in Older Adults: The Cardiovascular Health Study. Circulation. 2016; 133:147-155.

38. Carr A, Ory D. Does HIV Cause Cardiovascular Disease? PLoS Medicine. 2006; 3:e496.

39. Islam FM, Wu J, Jansson J, Wilson DP. Relative risk of cardiovascular disease among people living with HIV: a systematic review and meta-analysis. HIV medicine. 2012; 13:453-468.

40. Stang A. Critical evaluation of the Newcastle-Ottawa scale for the assessment of the quality of nonrandomized studies in meta-analyses. European Journal of Epidemiology. 2010; 25:603-605.

41. Zhu W, Meng YF, Wu Y, Xu M, Lu J. Association of alcohol intake with risk of diabetic retinopathy: a meta-analysis of observational studies. Sci Rep. 2017; 7:4.

42. Zhang YP, Li WQ, Sun YL, Zhu RT, Wang WJ. Systematic review with meta-analysis: coffee consumption and the risk of gallstone disease. Alimentary pharmacology \& therapeutics. 2015; 42:637-648.

43. DerSimonian R, Laird N. Meta-analysis in clinical trials. Control Clin Trials. 1986; 7:177-188.

44. Higgins JP, Thompson SG. Quantifying heterogeneity in a meta-analysis. Statistics in Medicine. 2002; 21:1539-1558.

45. Begg CB, Mazumdar M. Operating characteristics of a rank correlation test for publication bias. Biometrics. 1994; 50:1088-1101.

46. Egger M, Davey Smith G, Schneider M, Minder C. Bias in meta-analysis detected by a simple, graphical test. BMJ. 1997; 315:629-634.

47. Sterne JA, Sutton AJ, Ioannidis JP, Terrin N, Jones DR, Lau J, Carpenter J, Rucker G, Harbord RM, Schmid CH, Tetzlaff J, Deeks JJ, Peters J, et al. Recommendations for examining and interpreting funnel plot asymmetry in meta-analyses of randomised controlled trials. BMJ. 2011; 343:d4002.

48. Xiong J, Lin J, Wang A, Wang Y, Zheng Y, Sang X, Xu Y, $\mathrm{Lu} \mathrm{X}$, Zhao H. Tea consumption and the risk of biliary tract cancer: a systematic review and dose-response meta-analysis of observational studies. Oncotarget. 2017; 8:39649-39657. https://doi.org/10.18632/oncotarget.16963.

49. Zhao L, Zheng Z, Huang P. Diabetes mellitus and the risk of glioma: a meta-analysis. Oncotarget. 2016; 7:4483-4489. https://doi.org/10.18632/oncotarget.6605. 